\title{
Contribuição ao conhecimento da incidência da brucelose no Estado do Paraná (Brasil)。
}

\author{
Oscar K. Palmquist \\ Instituto de Biologia e Pesquisas Tecnológicas
}

\begin{abstract}
The author carried out an examination of brucellosis on the cattle of the State of Paraná (Brazil). In cow milk, an incidence of 7,90 percent was found, but a severe focus was located in Castro county (29,92 percent). In cattle, breaded extensively, the incidence was 16,49 percent. An higher percentage was located particular in the vicinity of the State of São Paulo, in which the livestock in general are kept on artificial pasturages. Sixty breeding farms were visited and 1716 samples of serum,sera from cattle were examined, as well as 797 sera from cow's milk.
\end{abstract}

Key Words: Brucellosis; State of Paraná; cow's milk

\section{A DOENÇA NO BRASIL}

A primeira referência a uma epizootia de brucelose bovina, no Brasil, se deve a ICIBACI (1922), que a constatou clinicamente, na Fazenda Pulador, Estado de São Paulo.

Porém, a demonstração definitiva da existência da doença no País é efetuada por MELLO e NEIVA (1930), que encontraram um índice de 38,27\% de reações positivas examinando 81 soros bovinos na Fazenda Modelo, Nova Odessa, São Paulo, com resultados comprovados pelo isolamento do agente causal.

Os mesmos autores, prosseguindo os trabalhos, examinaram mais 176 bovinos em diversas zonas daquele Estado e obtiveram 10,28\% de reagentes. TORRES (1931), examinando 51 soros de animais importados, encontrou $15,68 \%$ positivos.

CARNEIRO (1933), de 428 amostras de soros bovinos, em São Paulo, obteve 9,57\% positivos.
Segundo HORTA (1943), PENHA e PACHECO,independentemente, isolaram de suínos, amostras de Br. Suis, em São Paulo.

NEIVA (1934), de 414 amostras de soros bovinos daquele mesmo Estado, obteve $6,70 \%$ de aglutinações positivas.

MELLO (1935) isolou uma amostra de $B r$. abortus, obtida por hemocultura de uma vaca que havia abortado dias antes com provas sorológicas e alérgicas positivas.

PÊCEGO, HARDMANN e BIFONE (1936) isolaram e identificaram várias amostras de $B r$. suis e, em 1925, soro-aglutinações, em material coletado em matadouro, encontraram 46,83\% de resultados positivos.

MAGALHÃES (1937), em Minas Gerais, obteve aglutinações positivas em soros de bovinos da Fazenda Modelo de Pedro Leopoldo, próxima à Capital daquele Estado.

Conforme HORTA (1943), em 1939 TORRES e BRAGA, no Estado de Pernambuco, obtiveram algumas soro-aglutinações positivas em bovinos.

\footnotetext{
$\wp$ Artigo publicado no Arquivos de Biologia e Tecnologia, v. 7, pp. 3-8, 1952.
} 
NEVES e PERES, citados por HORTA (1943), em Minas Gerais, isolaram $\mathrm{Br}$. abortus do coração de um feto bovino e examinando o soro de 209 vacas da Fazenda Florestal do Governo do Estado, encontraram $29,33 \%$ positivos e $9,33 \%$ suspeitos. Segundo MOSCI (1944), em 1941, SOUZA, em Santa Catarina, diagnosticou sorologicamente a doença em bovinos, na Fazenda Assis Brasil, pertencente ao Governo do Estado.

FINAMORE e CORRÊA (1941), no Rio Grande do Sul, encontraram num plantel puro sangue a elevada percentagem de 39,56\% de aglutinações positivas. Em 546 animais procedentes dos Municípios de Bagé, Guaíba, Porto Alegre e Pelotas, naquele Estado, obtiveram 33,33\% de resultados positivos. Em outro lote de 894 bovinos, nos Municípios de Santa Maria, Cachoeira, Livramento, Jaguarão e Uruguaiana, o índice foi de $3,02 \%$.

MOSCI (1944), de 1912 soro-aglutinações executadas no Estado do Rio de Janeiro, encontrou os seguintes resultados: 441 amostras de soros bovinos colhidos no Matadouro da Penha - 1,33\% positivos e 4,08\% suspeitos; 81 amostras de soros bovinos de granja - 4,93\% positivos e 1,23\% suspeitos; 309 soros de suínos procedentes de várias regiões do País - 11,97\% positivos e 7,11\% suspeitos; 396 soros de caprinos $-2,02 \%$ positivos e $3,03 \%$ suspeitos; e em 185 soros de ovinos o índice foi de $1,08 \%$ positivos e suspeitos.

HIPÓLITO, SOUZA e GIOVINE (1943), em Minas Gerais, num total de 2411 amostras de soros, encontraram os seguintes resultados: 2065 soros de bovinos com índice de aglutinações de $8,04 \% ; 253$ soros de eqüinos com $6,07 \%$ positivos; 22 soros de suínos com $4,05 \%$ positivos e 71 soros de caprinos examinados resultaram negativos.

CORRÊA (1943) relata que, de 1937 a 1944, foram examinados no Rio Grande do Sul, 15104 bovinos com $7,13 \%$ de reações positivas.

\section{MATERIAL E TÉCNICA}

O levantamento que nos propusemos realizar tem por objetivo conhecer o estado em que se encontra o rebanho paranaense no tocante à brucelose.

Foram percorridos 18 Municípios do Estado do Paraná (Brasil) e visitadas 60 Fazendas de criação de gado bovino, nas quais examinamos 1716 animais submetidos a regime extensivo de criação. De outro lado, visitamos, também, 65 estábulos de vacas leiteiras, nos quais examinamos 797 soros de bovinos.
Adotamos a técnica recomendada pelo Animal Diseases Station - National Agricultural Research Center - Beltsville, Maryland, U.S.A.

O sangue era colhido por punção da jugular e, após coagulação, o soro submetido às provas de aglutimação pelo método rápido.

Igualmente, o antígeno foi preparado de acordo com a técnica acima aludida.

O critério adotado na leitura dos resultados foi: positivo para a aglutinação igual ou superior a 1:25 e negativo abaixo desse título.

O Quadro 1 revela o índice nas duas principais fontes de leite e derivados do Paraná.

\section{QUADRO 1 - GADO LEITEIRO MANTIDO EM REGIME DE SEMI-ESTABULAÇÃO}

\begin{tabular}{|c|c|c|c|c|c|}
\hline \multirow{2}{*}{ 产 } & \multirow{2}{*}{ 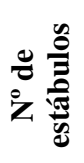 } & \multirow{2}{*}{ 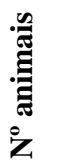 } & \multicolumn{2}{|c|}{ Resultados } & \multirow{2}{*}{$\%$} \\
\hline & & & Positivo & Negativo & \\
\hline Curitiba & 57 & 660 & 22 & 638 & 3,33 \\
\hline Castro & 8 & 137 & 41 & 96 & 29,92 \\
\hline TOTAL & 65 & 797 & 63 & 734 & 7,90 \\
\hline
\end{tabular}

O Quadro 2 mostra o índice encontrado por Município, em gado criado extensivamente.

QUADRO 2 - GADO CRIADO EM REGIME EXTENSIVO

\begin{tabular}{|c|c|c|c|c|c|}
\hline \multirow{2}{*}{ 器 } & \multirow{2}{*}{ 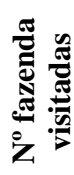 } & \multirow{2}{*}{ 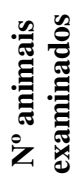 } & \multicolumn{2}{|c|}{ Resultados } & \multirow{2}{*}{$\%$} \\
\hline & & & Posit. & Negat. & \\
\hline Araucária & 3 & 28 & 11 & 17 & \\
\hline Bandeirantes & 2 & 141 & 22 & 119 & \\
\hline Cambará & 1 & 21 & 8 & 13 & \\
\hline Cornélio Procópio & 1 & 47 & 24 & 23 & \\
\hline Carlópolis & 1 & 13 & 11 & 2 & \\
\hline Castro & 7 & 139 & 13 & 126 & \\
\hline Guarapuava & 2 & 60 & 4 & 56 & \\
\hline Jacarezinho & 9 & 598 & 135 & 463 & \\
\hline Jaguariaíva & 2 & 18 & 10 & 8 & \\
\hline Lapa & 2 & 16 & 0 & 16 & \\
\hline Paranaguá & 1 & 33 & 0 & 33 & \\
\hline Ponta Grossa & 4 & 170 & 14 & 156 & \\
\hline Palmeira & 5 & 74 & 0 & 74 & \\
\hline Piraquara & 2 & 33 & 1 & 32 & \\
\hline Palmas & 5 & 65 & 1 & 64 & \\
\hline Porto Amazonas & 7 & 16 & 0 & 16 & \\
\hline $\begin{array}{l}\text { Sto. Antônio da } \\
\text { Platina }\end{array}$ & 4 & 228 & 25 & 203 & \\
\hline $\begin{array}{l}\text { São José dos } \\
\text { Pinhais }\end{array}$ & 2 & 16 & 4 & 12 & \\
\hline TOTAL & 60 & 1716 & 283 & 1433 & 16,49 \\
\hline
\end{tabular}




\section{COMENTÁRIOS}

Uma análise dos resultados revela que o gado leiteiro de Curitiba (Paraná-Brasil) apresenta um índice relativamente baixo de infecção $(3,33 \%)$, especialmente se considerarmos que examinamos aproximadamente um terço do rebanho fornecedor de leite desta Capital.

O rebanho da Cooperativa de Leite de Castro, uma das principais do Estado, ao contrário, reflete um grau elevado de infecção $(29,92 \%)$, embora as condições higiênicas das instalações daquela organização se apresentem satisfatórias. Essa cifra contrasta com os resultados encontrados naquele mesmo Município, em que o gado criado em regime extensivo de pastagens naturais apresentou índice de $9,35 \%$ de reagentes.

Os Municípios de Bandeirantes, Cambará, Cornélio Procópio, Carlópolis, Jacarezinho e Jaguariaíva, cujo rebanho apresenta elevado grau de infecção em relação aos demais, estão situados nas proximidades ou mesmo nas fronteiras com o Estado de São Paulo. O intenso intercâmbio de gado bovino daquele Estado com Municípios limítrofes do Estado do Paraná têm ocasionado considerável disseminação da zoonose naquela região.

Nos Municípios situados para o Sul e Oeste do Estado, o índice baixa consideravelmente, queremos crer, pelas dificuldades de penetração do rebanho paulista e onde o intercâmbio de gado é feito somente entre Municípios vizinhos.

\section{RESUMO}

O rebanho bovino paranaense apresenta um índice de brucelose relativamente alto, particularmente no Norte e Leste do Estado. O gado leiteiro revelou um índice de 7,90\%, com um foco grave no Município de Castro $(29,92 \%)$. Bovinos criados em regime extensivo de pastagens naturais se apresentam com menor grau de infecção, pois a maior incidência foi encontrada no Norte do Estado, onde, regra geral, os campos são constituídos de pastos artificiais.

\section{REFERÊNCIAS}

CARNEIRO, V. (1933), Em torno da febre ondulante. Brucelose bovina e sua freqüência em São Paulo. $R$. Soc. Paulista de Med. Vet., São Paulo, 3 (5-6) : 126.

CORREA, O. (1943), A Brucelose no Rio Grande do Sul. Aspecto clínico e profilático. Anais do II Congresso Brasileiro de Veterinária, p. 241.

FINAMORE e CORRÊA (1941), Cit. in Parreiras Horta (1943), Bruceloses. Imprensa Médica, 19 (358) : 55.

HIPÓLITO, O.; SOUZA, R. e GIÓVINE, N. (1943), Brucelose e soro-aglutinação em Minas Gerais. Anais do II Congresso Brasileiro de Veterinária, p. 235.

HORTA, P. P. (1943), Bruceloses. Imprensa Médica, 19 (358) : 45.

ICIBACI, T. (1922), Aborto contagioso bovino no Estado de São Paulo. I Congresso Nacional de Medicina Veterinária, p. 197.

MAGALHÃES, O. (1937), Febre de Malta (nota prévia). Brasil Médico, p. 1247.

MELLO, A. e NEIVA, C. (1930), Moléstia de Bang em São Paulo. Rev. Ind. Animal, 1 (4-5).

MELLO, A. (1935), A febre ondulante em São Paulo. Separata da Revista de Indústria Animal.

MOSCI, A. (1944), Em torno da incidência das Bruceloses em animais. Bol. Soc. Bras. Medicina Veterinária, 12 (2) : 105.

NEIVA, A. (1934), Aglutininas para o gênero Brucella em soro de animais. Rev. Ind. Animal, 2 (1) : 81.

PÊCEGO, O.; HARDMANN, E. e BIFONE, J. (1936), Contribuição ao estudo da infecção brucélica nos suínos. Folha Veterinária, 1 (50) : 70.

TORRES, S. (1931), Moléstia de Bang. Rev. Zootecnia e Veterinária, 17 (1) : 49. 